\title{
A Participatory Workplace Intervention for Employees With Distress and Lost Time: A Feasibility Evaluation Within a Randomized Controlled Trial
}

\author{
Sandra H. van Oostrom • Willem van Mechelen • \\ Berend Terluin - Henrica C. W. de Vet . \\ Johannes R. Anema
}

Published online: 24 March 2009

(c) The Author(s) 2009. This article is published with open access at Springerlink.com

\begin{abstract}
Introduction Little is known about feasibility and acceptability of return to work (RTW) interventions for mental health problems. RTW for mental health problems is more complicated than for musculoskeletal problems due to stigmatization at the workplace. A participatory workplace intervention was developed in which an employee and supervisor identify and prioritize obstacles and solutions for RTW guided by a RTW coordinator. This paper is a feasibility study of this innovative intervention for employees with distress. The aims of this study were to describe the reach and extent of implementation of the workplace intervention, the satisfaction and expectations of all stakeholders, and the intention to use the workplace intervention in the future. Methods Eligible for this study were employees who
\end{abstract}

S. H. van Oostrom · W. van Mechelen · J. R. Anema $(\bowtie)$ Department of Public and Occupational Health and the EMGO Institute for Health and Care Research, VU University Medical Center, van der Boechorststraat 7, 1081 BT Amsterdam,

The Netherlands

e-mail: h.anema@vumc.nl

S. H. van Oostrom - W. van Mechelen · J. R. Anema Body@Work, Research Center Physical Activity, Work and Health, TNO-VU University, Amsterdam, The Netherlands

W. van Mechelen · J. R. Anema

Research Center for Insurance Medicine AMC-UWV-VU

University Medical Center, Amsterdam, The Netherlands

B. Terluin

Department of General Practice and the EMGO Institute for Health and Care Research, VU University Medical Center, Amsterdam, The Netherlands

H. C. W. de Vet

Department of Epidemiology and Biostatistics and the EMGO Institute for Health and Care Research, VU University Medical Center, Amsterdam, The Netherlands had been on sick leave from regular work for 2-8 weeks with distress. Data were collected from the employees, their supervisors, RTW coordinators, and occupational physicians by means of standardized matrices and questionnaires at baseline and 3 months follow-up. Reach, implementation, satisfaction, expectations, and maintenance regarding the workplace intervention were described. Results Of the 56 employees with distress eligible to receive the workplace intervention, 40 employees, their supervisors and RTW coordinators actually participated in the intervention. They identified 151 obstacles for RTW mostly related to job design, communication, mental workload and person-related stress factors. The 281 consensus-based solutions identified were mostly related to job design, communication and training. Of those solutions, $72 \%$ was realized at the evaluation with the employee and supervisor. Overall, employees, supervisors and occupational health professionals were satisfied with the workplace intervention and occupational health professionals rated it with a 7.1. Timeinvestment was the only barrier for implementation reported by the occupational health professionals. Conclusions The results of this study indicate a high feasibility for a broad implementation of a participatory workplace intervention for employees with distress and lost time, and their supervisors.

Keywords Distress - Workplace intervention . Feasibility - Return to work - Implementation . Mental health
Abbreviations
RCT Randomized controlled trial
$\mathrm{OH}$ Occupational health
RTW Return to work 
LBP Low back pain

OP Occupational physician

\section{Introduction}

Many randomized controlled trials (RCTs) have been conducted in the field of occupational health $(\mathrm{OH})$, but in general, those trials provide little information about the content and degree of implementation of the interventions in question [1, 2]. However, the implementation and feasibility aspects of interventions are of critical importance, since they address the issue of how easily an intervention can be implemented in practice and how well the intervention is received. This information makes it possible for care providers and researchers to determine whether the findings of a study apply to their local setting, population and country [3]. These are important aspects in view of the difficulties that are encountered when transferring evidence into practice [4], also in mental health [5].

In fact, an intervention has to be both effective and feasible. Effective interventions that are not feasible to be implemented are useless in practice, and the same applies to interventions that are feasible to be implemented but lack effectiveness. The need for knowledge about the implementation and feasibility of an intervention has been recognized by many authors since the beginning of this decade $[6,7]$. However, the number of feasibility studies alongside RCTs in the field of occupational health is very limited $[1,8,9]$.

The present paper is a feasibility study of a participatory workplace intervention for sick-listed employees with distress. The workplace intervention is a stepwise process to identify and solve obstacles for return to work (RTW), based on consensus between a sick-listed employee and his or her supervisor. The participatory workplace intervention is an innovative approach in mental health. Evidence shows that medical interventions without consideration of the work situation do not show a positive effect on RTW outcomes [10,11]. A return to an unchanged work situation of an employee with mental health problems may be doomed to fail and may even lead to longer-term recurrences $[12,13]$. Therefore, it is recommended that RTW interventions should be carried out close to the workplace and in collaboration with the key stakeholders $[1,14]$.

The workplace intervention was based on a successful RTW intervention for sick-listed employees with low back pain (LBP) $[15,16]$, and was further tailored to the needs of sick-listed employees with distress by applying the Intervention Mapping approach [17]. Due to stigmatization at the workplace RTW of employees with distress is more complicated than for musculoskeletal problems [18]. The feasibility and implementation of an intervention are factors to be considered as part of the evaluation in Intervention Mapping [19]. Through small-scale consideration of these aspects, factors that impede large-scale implementation can be identified and, if necessary, improved to facilitate a largescale implementation.

The aims of this study were (1) to describe the reach of the workplace intervention; (2) to describe whether the workplace intervention was implemented as planned, including a description of perceived barriers for implementation; (3) to describe the satisfaction and expectations of employees, supervisors, and $\mathrm{OH}$ professionals; and (4) to describe whether $\mathrm{OH}$ professionals reported the intention to use the workplace intervention in the future.

\section{Methods}

This feasibility study was carried out as part of a RCT on the effectiveness of a participatory workplace intervention for sick-listed employees with distress, the ADAPT study [20]. The Medical Ethics Committee of the VU University Medical Center approved the study and all participants signed informed consent.

\section{Study Population}

Eligible for this study were employees who had been on sick leave from regular work for 2-8 weeks with distress, and were selected by a three-item distress screener based on the four-dimensional symptom questionnaire (4DSQ) $[20,21]$. The distress screener correlated high $(0.82)$ with the 4DSQ distress scale. Sensitivity and specificity of the distress screener were, respectively, 0.85 and 0.78 [22].

The study population encompassed both criteria-based psychiatric disorders (mostly depressive and anxiety disorders) and 'subthreshold' disorders (including adjustment disorders). It is generally known that distress can coexist with chronic diseases and/or physical symptoms, therefore a group of distressed participants with heterogeneous health conditions was selected. Exclusion of employees occurred in case of (1) a conflict between the employee and the employer with legal involvement; (2) working less than $12 \mathrm{~h}$ a week; (3) pregnancy; (4) sick-listed for more than 8 weeks; (5) another episode of sick leave within 1 month before the current episode; and (6) inability to complete questionnaires written in the Dutch language. Occupational physicians (OPs) excluded employees with severe psychiatric disorders (mania, psychosis or suicidal) or a terminal illness from starting the workplace intervention. The Improved Gatekeeper's Act mandates the employer to formulate a plan for RTW with the employee at 8 weeks of sick leave. If this plan is formulated, it is more difficult to initiate other interventions. 
This paper focussed on the first 40 participants who had actually started to participate in the workplace intervention, which means that only part of the recruitment sample was considered.

\section{Workplace Intervention}

The workplace intervention consisted of a stepwise process to identify and solve obstacles for RTW, based on consensus between the sick-listed employee and his or her supervisor. The intervention was guided by a RTW coordinator from the respective occupational health services, i.e., a company social worker or a labour expert. In the Netherlands, a labour expert is a specialist in occupational health and work processes who helps sick-listed employees to RTW. Although, the RTW coordinators were employed by private occupational health services, they are indirectly paid by employers. However, Dutch regulations guarantee the independency of the RTW coordinators.

The RTW coordinator planned three meetings on 1 day. In the first meeting, the employee performed a task analysis and identified obstacles for RTW in a structured conversation with the RTW coordinator. These obstacles were ranked according to priority, based on their frequency and perceived severity. In the second meeting, the supervisor identified obstacles for RTW from the perspective of the supervisor. The procedure of the meeting between the supervisor and the RTW coordinator was the same as in the meeting between the employee and the RTW coordinator. In the third meeting, the employee, the supervisor and the RTW coordinator were jointly involved in brainstorming for solutions. The solutions were ranked according to priority, based on feasibility, solving capability and short-term applicability of the suggested solution. Then a plan for realization of the suggested solutions was formulated, including the person responsible for the realization, how the solution was planned, and when it should be realized. This plan was based on consensus. In the weeks following the meetings the solutions could be realized. If required, an RTW coordinator planned a visit to the workplace to instruct and advise the employee. One month after the meetings, actual realization of the solutions and contributions to RTW were evaluated by the RTW coordinator with the employee and the supervisor. This workplace intervention has been described in detail in other papers [15, 20]. Fig. 1 presents an example of the application of the workplace intervention.

\section{Data Collection}

The data for this study were collected by questionnaires (at baseline, at the 3 month follow-up, and when all 40 workplace interventions had been completed) and standardized matrices (as shown in Fig. 1). The concepts used were partly based on RE-AIM, a framework that recognizes several objectives for the evaluation of interventions [23]. Effectiveness of the workplace intervention was not assessed in this feasibility study, these results will become available in the near future.

\section{Reach}

Reach was addressed at setting level and at participants' level. At setting level, reach is defined as the number of settings and the representativeness of the settings (companies and $\mathrm{OH}$ professionals) participating in the research. At participants' level, reach is defined as the number of employees and the representativeness of the employees who participated in the research. Reasons for non-participation were registered. All participants completed a baseline questionnaire, providing demographic information, information about symptom severity, and job characteristics.

\section{Implementation of the Workplace Intervention}

Implementation concerns the extent to which the intervention was provided as intended (i.e., as described in the intervention manual) [23]. Complete implementation of the workplace intervention was achieved if the three meetings between the RTW coordinator, employee and supervisor had actually taken place and if the standardized matrices had been accurately completed by the RTW coordinators. The number of employees who did not actually participate in the workplace intervention and the reasons given were registered.

At the 3 month follow-up, an intervention evaluation questionnaire was sent to the employee, the supervisor, and the $\mathrm{OH}$ professionals (i.e., the RTW coordinator and the OP). The questions concerned the intervention process, the satisfaction with the intervention, the work adaptations that were selected, and the perceived effect of these work adaptations. The RTW coordinators also provided data about the timing and duration of the intervention and these were compared with the intervention manual. Information concerning obstacles for RTW, solutions and the RTW plan discussed in the meetings was collected on the standardized matrices, which were completed by the RTW coordinator, based on the agreements made during the meetings. All obstacles and solutions for RTW were classified based on the ergonomic abstracts classification scheme and the definition of work organization in the National Occupational Research Agenda of the National Institute for Occupational Safety and Health [15, 24, 25]. The classification categories were: workplace design; work design and organization (tasks, schedules, communication, training, management style, use of support, organizational characteristics); environment; and task-related factors 
Fig. 1 Case description

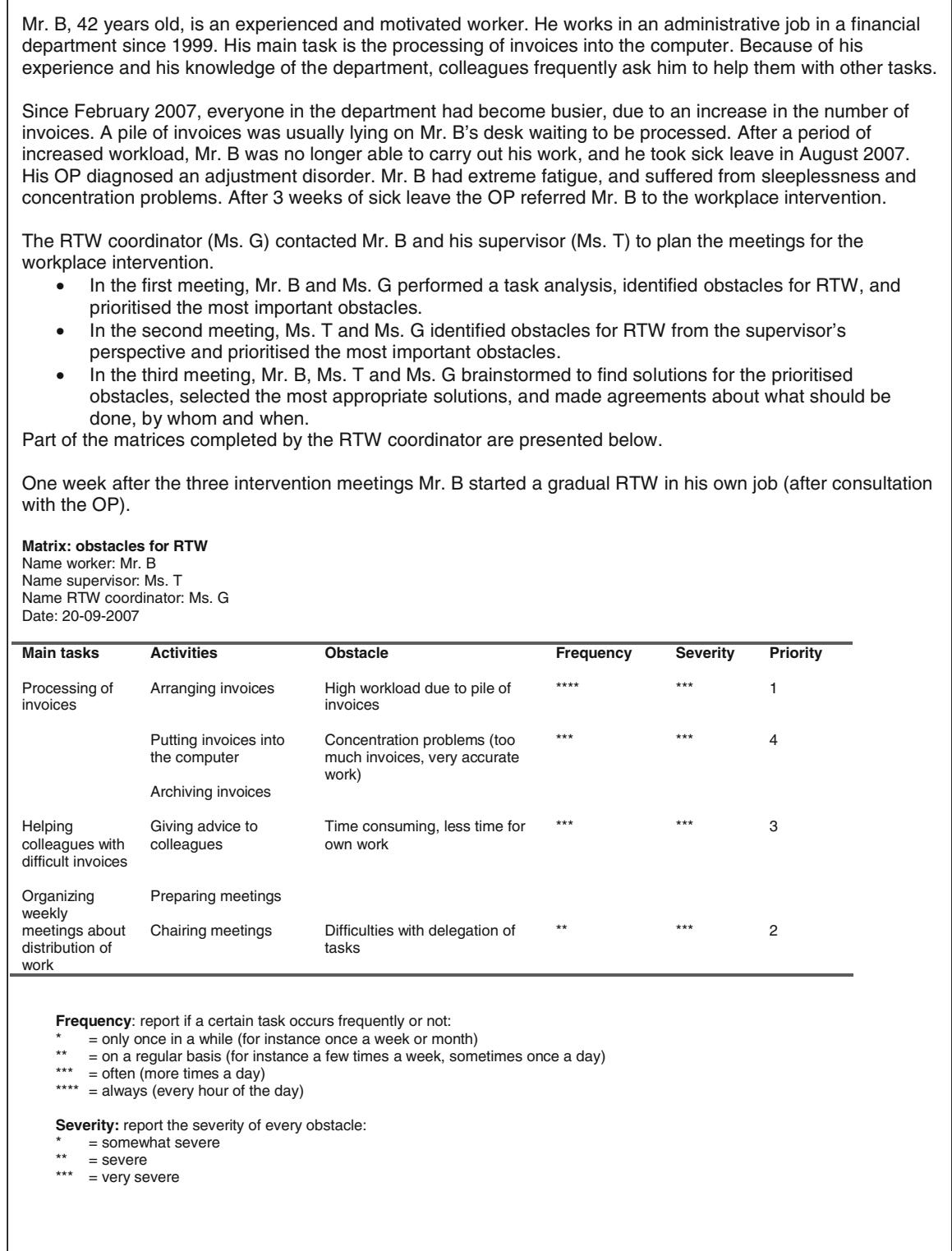

(mental workload, physical workload, person-related stress).

When all 40 workplace interventions had been completed, an implementation questionnaire focussing on barriers and facilitators for implementation of the intervention was sent to all OPs and RTW coordinators [26, 27].

\section{Satisfaction, Usefulness and Expectations}

Satisfaction after participation in the workplace intervention, perceived usefulness of the intervention and expectations for RTW (and symptom recovery) was requested from all stakeholders in the 3 month follow-up questionnaire. Whether employees felt that they had been taken seriously by the OP and the RTW coordinator was measured with the short version of the Patient Satisfaction with Occupational Health Services Questionnaire [28], which consists of a five-point scale ranging from no agreement to full agreement.

\section{Maintenance}

Maintenance is defined as the intention of $\mathrm{OH}$ professionals to support the implementation of the workplace intervention in the future. Actual maintenance could not be measured because large-scale implementation was not the purpose of this study. Therefore, questions were asked about intentions for future use in the implementation questionnaire for $\mathrm{OH}$ professionals. This questionnaire also included questions about the $\mathrm{OH}$ professionals' view on the 
Fig. 1 continued

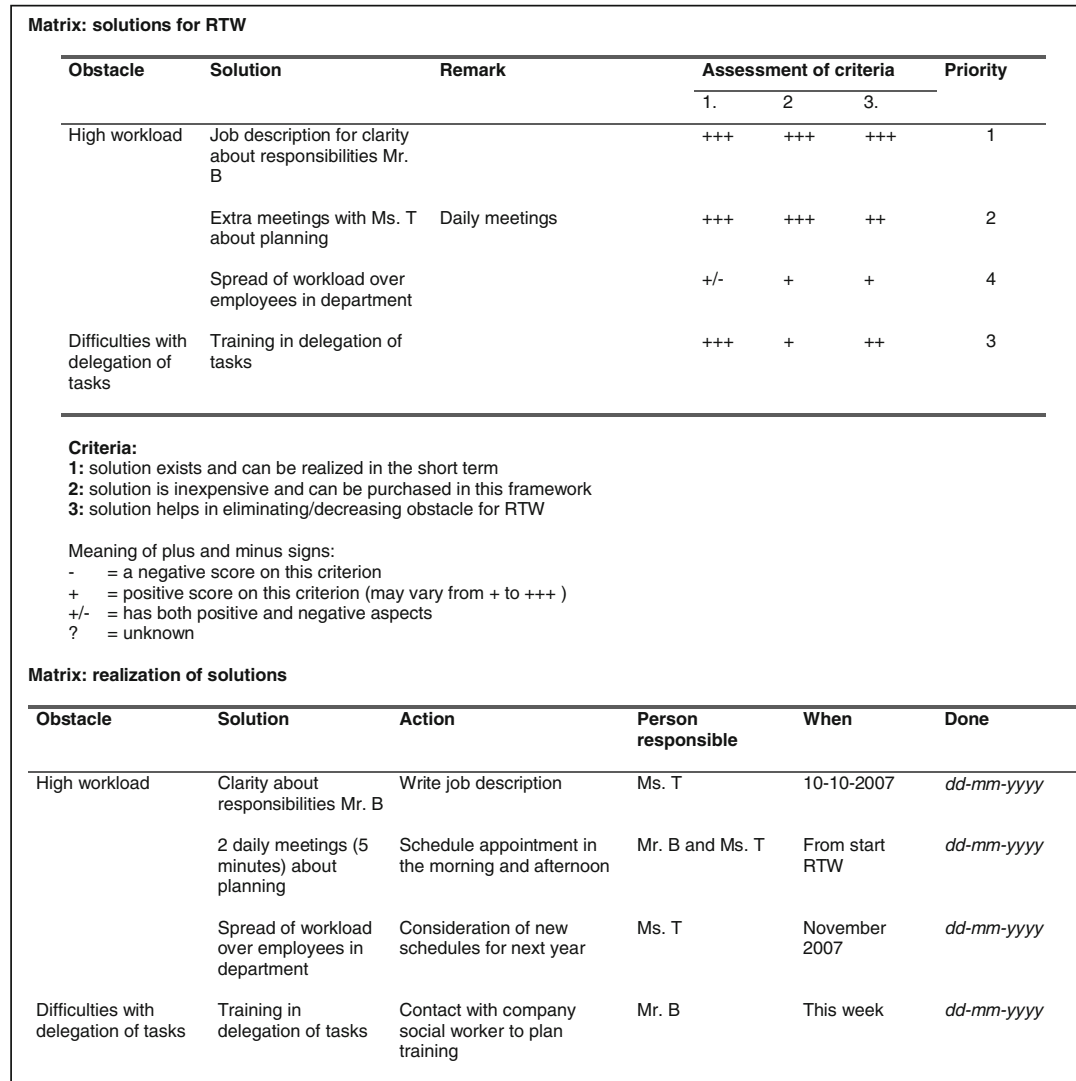

applicability of the intervention for sick-listed employees with distress.

\section{Data Analysis}

The data were analyzed by means of descriptive statistics. Differences between participants and non-participants were tested with $t$-tests and the Pearson Chi-Square test. Excel 2003 and SPSS version 15.0 were used for the descriptive and statistical analyses.

Obstacles and solutions for RTW as registered in the matrices were classified by two researchers independently. Disagreements between researchers with regard to classified obstacles and solutions were discussed and, if necessary, a third researcher was consulted.

\section{Results}

\section{Reach}

\section{Setting Level}

Three occupational health services were invited to participate in the ADAPT study. Two occupational health services responded positive. The remaining one responded with substantial doubts related to the time investment for the $\mathrm{OH}$ professionals. The researchers therefore decided to proceed with the two positive occupational health services, which were connected to three large companies from the industrial, health care, education, and research sectors ( $n \approx 20.000$ employees).

Of the 13 RTW coordinators who were invited for training in the workplace intervention, one was not motivated before and one did not feel capable to conduct the intervention after participating in the training. Due to slow recruitment rates, one RTW coordinator decided during the course of the study not to continue with the intervention and another one retired before a first participant was referred to her. All 14 OPs from the participating occupational health services participated in the ADAPT study.

\section{Participants Level}

Figure 2 shows the flow diagram of employees in the ADAPT study. Approximately, 8,500 screeners were sent to sick-listed employees. Based on the screeners that were returned, 744 employees were eligible for participation in the study. When 568 were contacted by phone, 456 were unwilling to participate or could not participate for other 
Fig. 2 Flow diagram of employees in the ADAPT study, including reasons for nonparticipation

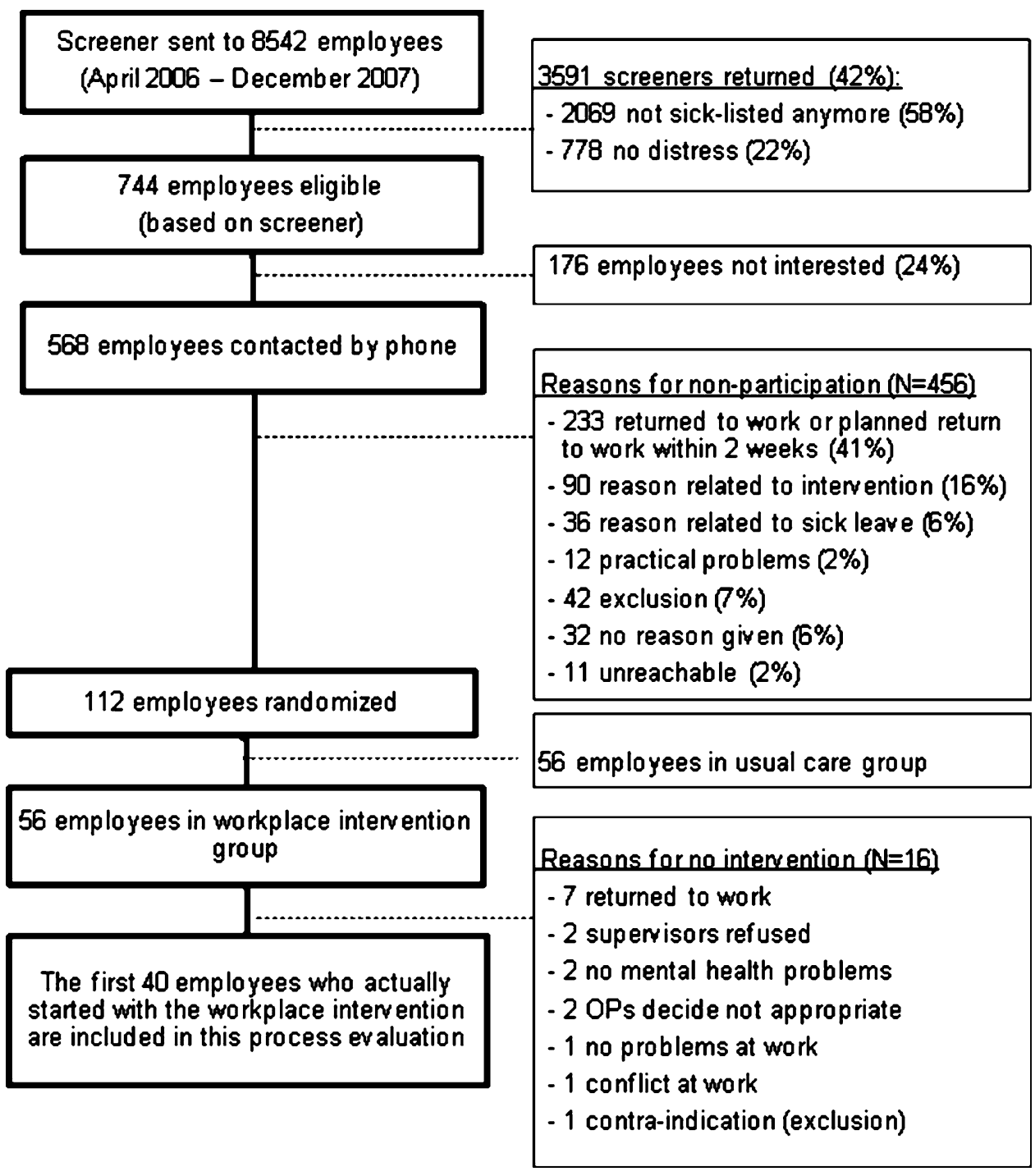

reasons. The main reason for non-participation (41\%) was a RTW or RTW planned within 2 weeks. Other reasons for non-participation were most frequently related to the intervention (time-restrictions, burden, satisfied with current treatment) and the reason for sick leave (private problems, elective surgery). In fact, 298 (65.4\%) employees could not participate and 158 (34.6\%) employees refused to participate. Finally, 112 participants were randomised. There were no differences in age or gender between participants and non-participants. However, excluding the employees who returned to work, men were more likely to participate than women $(P=0.005)$. Of those randomised to the intervention group $(N=56), 40$ actually started participating in the intervention and their data were used for this study. The baseline characteristics of those employees are shown in Table 1.
Implementation of the Workplace Intervention

Among the employees in the intervention group, the most often reported reason for not starting to participate in the intervention was RTW; four employees returned to their previous job and three employees returned to a new job. Other reasons are shown in Fig. 2. One employee started participating in the intervention but neither the employee nor the supervisor could identify obstacles for RTW. Therefore, complete protocol implementation was eventually accomplished for 39 employees. For three participants there was no evaluation of the realization of solutions by phone. Optional meetings for instructions at the workplace took place seven times, and additional meetings with the RTW coordinator took place six times. 
Table 1 Baseline characteristics of employees who started participating in the workplace intervention

\begin{tabular}{|c|c|}
\hline Baseline characteristics & $N=40$ \\
\hline \multicolumn{2}{|l|}{ Employee characteristics } \\
\hline Mean age $(\mathrm{SD})$ in years & $47.9(7.6)$ \\
\hline Gender ( $\%$ male $)$ & 82.5 \\
\hline Married or cohabiting (\%) & 80.0 \\
\hline \multicolumn{2}{|l|}{ Level of education (\%) } \\
\hline Low & 25.0 \\
\hline Intermediate & 50.0 \\
\hline High & 25.0 \\
\hline \multicolumn{2}{|l|}{ Distress (4DSQ score) } \\
\hline$\%$ above threshold $(>10)$ & 89.7 \\
\hline \multicolumn{2}{|l|}{ Depression } \\
\hline$\%$ above threshold $(>2)$ & 47.5 \\
\hline \multicolumn{2}{|l|}{ Anxiety } \\
\hline$\%$ above threshold $(>7)$ & 36.8 \\
\hline \multicolumn{2}{|l|}{ Somatization } \\
\hline$\%$ above threshold $(>10)$ & 65.8 \\
\hline \multicolumn{2}{|l|}{ Work-related characteristics } \\
\hline \multicolumn{2}{|l|}{ Occupation $(\%)$} \\
\hline Mentally demanding & 40.0 \\
\hline Physically demanding & 35.0 \\
\hline Mixed mentally and physically demanding & 12.5 \\
\hline Light physically or light mentally demanding & 12.5 \\
\hline \multicolumn{2}{|l|}{ Work schedule $(\%)$} \\
\hline Shift work & 27.5 \\
\hline Irregular work/flexible schedules & 2.5 \\
\hline Day work & 70.0 \\
\hline
\end{tabular}

\section{Timeline and Duration of the Workplace Intervention}

The time schedule for starting the intervention was properly followed. However, the first three meetings were not all planned on 1 day for 17 of the 39 participants. For those 17 employees the median time between the three meetings was 12 calendar days (IQR 3-23 days). The median time between the workplace intervention meetings and the evaluation was 56 calendar days (IQR 38-87 days) for the 36 employees for whom an evaluation was conducted. The intervention manual described a 1 month period between the meetings and the evaluation. The delay that occurred was due to RTW coordinator preferences or a delayed visit to the workplace. In total, the three meetings (of the RTW coordinator with the employee, the supervisor, and the employee and supervisor together) lasted for an average of $3 \mathrm{~h}$ and $45 \mathrm{~min}$. The median time investment for the complete workplace intervention for the RTW coordinator was $7 \mathrm{~h}$ (IQR 5.5-8.4 h), including the time needed for administration.

\section{Implementation of the Workplace Intervention Process}

The RTW coordinators and OPs reported that, respectively, $89-92 \%$ of the 40 employees were cooperative regarding participation in the workplace intervention. Over $60 \%$ of the employees actively participated, according to the RTW coordinators. The supervisors were also cooperative in $84 \%$ of the cases, according to the OPs. From the RTW coordinators point of view, $98 \%$ of the employees had a sufficient say in the workplace intervention process.

A total of 151 obstacles for RTW were identified, most of which were related to job design (13\% of all obstacles), communication $(13 \%)$, mental workload $(17 \%)$, physical workload (10\%), and person-related stress factors $(22 \%)$, such as perfectionism and a high sense of responsibility. Subsequently, 281 solutions for RTW were identified and those most frequently mentioned are presented in Fig. 3. Most of the solutions were classified into the categories of job design (e.g., task rotation, skip task temporarily), communication (e.g., feedback from supervisor, regular meetings with supervisor) and training (e.g., time management, skills training). The highest priority obstacles and solutions showed very similar results: the highest priority obstacles were mental workload (16\% of all obstacles) and person-related stress factors $(24 \%)$; the highest priority solutions were communication ( $20 \%$ of all solutions) and training $(20 \%)$.

In $56 \%$ of the 281 solutions the person responsible for the initiation of actions was the employee and in $36 \%$ it was the supervisor. Seventy five percent of the solutions could be

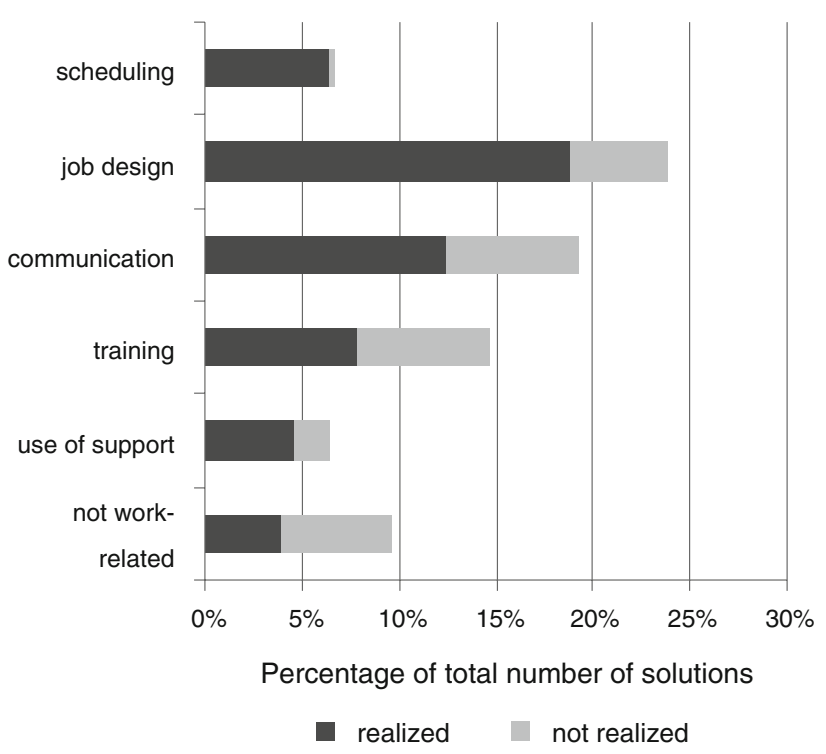

Fig. 3 The six categories to which most solutions were allocated, as a percentage of the total number of solutions reported in the matrices. The bars differentiate the solutions realized and not realized at the time of the evaluation, according to the employee and the supervisor 
realized in the short-term (within 3 months), but for $16 \%$ of the solutions no clear timeline could be indicated, for instance if a solution could only be realized after actual RTW. The evaluation showed that $72 \%$ of the solutions were realized according to the employee and the supervisor. Of the 281 solutions, $28 \%$ had not been realized at the time of evaluation, in $10 \%$ of the solutions because another solution was found, and in $2 \%$ of the solutions because a new obstacle for RTW was experienced by the employee and as a consequence the initial solution was inappropriate. Of the obstacles $(N=37)$ and solutions $(N=66)$ with the highest priority, $\sim 70 \%$ were realized at the time of the evaluation, according to the employee and the supervisor.

\section{Barriers and Facilitators for the Realization of the Solutions}

With regard to realization of the solutions, the relationship between the employee and the supervisor, the employee's motivation to work, and the opportunities for work adaptation were most often rated as facilitating factors. Mentally demanding work and the mental capacity of the employee were considered by the $\mathrm{OH}$ professionals to be barriers for the realization of solutions.

\section{Barriers and Facilitators for the Implementation of the Workplace Intervention}

After each workplace intervention, $\mathrm{OH}$ professionals rated the factors that impeded and facilitated the process of the workplace intervention. Compliance, commitment, and influence of both the employee and the supervisor were regarded as the most important factors that were positively related to the process of the intervention.

On a broader level, $\mathrm{OH}$ professionals rated the presence of various implementation factors for the workplace intervention (Table 2). Except for time investment and scientific basis, all factors were clearly rated as present, and therefore influenced implementation positively. With regard to the timing of the start of the intervention, immediate application when sick leave occurs was recommended by 8 of the $18 \mathrm{OH}$ professionals, because in the ADAPT study the intervention was sometimes applied too late to be of any use. Finally, the standardized matrices were considered to be too extensive.

\section{Satisfaction, Usefulness and Expectations}

The workplace intervention was expected by most OPs and RTW coordinators to have no effect on time until RTW (respectively, for 60 and 54\% of the 40 employees). Sustainable RTW was expected to be positively influenced by the intervention for, respectively, $55-74 \%$ of the
Table 2 Presence of innovation, care provider, and context level barriers for implementation, rated by the $\mathrm{OH}$ professionals $(n=18)$

\begin{tabular}{lll}
\hline Level & Factor & Mean score $(1-5)^{\mathrm{a}}$ \\
\hline Innovation & Compatibility & 1.3 \\
& Time investment & 3.6 \\
& Flexibility & 1.7 \\
& Complexity & 2.0 \\
& Scientific basis & 2.8 \\
OH professional & Attitude & 1.2 \\
& Knowledge & 1.3 \\
& Expertise & 1.4 \\
& Doubts innovation & 2.1 \\
& Work style & 1.8 \\
Context & Perceived advantage & 2.0 \\
& Support colleagues & 1.7 \\
& Resistance employees & 1.9 \\
& Resistance supervisors & 2.1 \\
\hline
\end{tabular}

$\overline{{ }^{a} \text { Scale ranged from no barrier perceived (1) to perceived as barrier (5) }}$

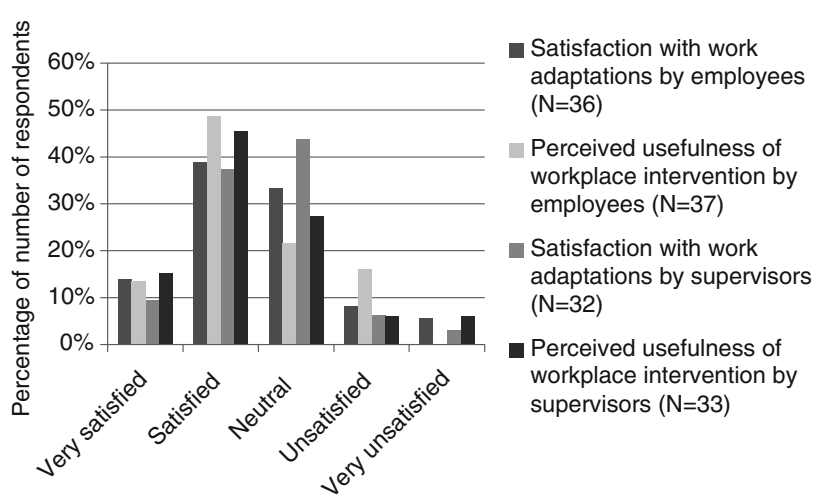

Fig. 4 Satisfaction and perceived usefulness rated on a 1-5 scale by the employees and the supervisors as a percentage of the number of respondents

employees. More than half of the employees and two-thirds of the supervisors expected the intervention to have positive effects on RTW. Even though the workplace intervention focused on RTW, the expectations of the OPs with regard to recovery of symptoms were positive for almost one-third of the employees. The usefulness of the workplace intervention and satisfaction with the work adaptations were most frequently rated positively by the employees and the supervisors (Fig. 4).

The $\mathrm{OH}$ professionals were satisfied with the process of the workplace intervention and rated this on average as 7.1 (scale 1-10; 10 indicating maximum satisfaction). Being taken seriously by the OP and the RTW coordinator was positively rated by the employees as a score of 3.4 and 3.9, respectively, (scale 1-5; 5 indicating maximum). The presence of the RTW coordinator was viewed as a positive influence on feelings of safety and support, according to 
employees and RTW coordinators, whereas the supervisors and RTW coordinators thought that it led to less perceived differences in authority between employees and supervisors.

\section{Maintenance}

All $18 \mathrm{OH}$ professionals reported that they intended to refer to or apply the workplace intervention in the future. Application of the intervention by RTW coordinators was preferred because the intervention is too time consuming for OPs. Application of the intervention was favored for communication problems, work-related barriers for RTW, passive or nonassertive employees, and stagnation of RTW. Application was considered to be inappropriate for actual conflicts at work (without legal involvement), good communication about RTW between the employee and the supervisor, and nonwork-related problems (just personal problems).

\section{Discussion}

The aim of this paper was to describe the reach, implementation, satisfaction, expectations, and maintenance of a workplace intervention for sick-listed employees with distress. Overall, the results of this study indicated good satisfaction of all stakeholders and high feasibility with regard to implementation.

\section{Comparison with Other Studies}

Obstacles for RTW mentioned by sick-listed employees with distress and their supervisors differ from the obstacles for RTW reported in LBP studies [15, 29]. Physical workload and problems related to workplace design were often reported as obstacles in the LBP studies, whereas most of the obstacles for RTW in the present study concerned mental workload and stress. Communication obstacles were often found for employees with distress, but these were not reported for LBP [15, 29]. With regard to the type of solutions for RTW, work design and organization were popular in this study, which is comparable with the results of LBP studies [15]. In LBP studies many solutions were also found in the workplace design and equipment category $[15,29,30]$. For the participants with communication problems in our study, simple opportunities for improvement were mainly proposed, such as scheduled meetings with the supervisor. The level of realization of the solutions in this study was considerably higher than in the LBP studies $[15,29]$. The differences in obstacles and solutions between the employees with distress and the LBP studies are not surprising, given the nature of these work disability conditions. Comparison with mental health studies that incorporated work adaptations in their interventions is impossible, due to a lack of information in these studies [31, 32].

Subsequent to the earlier demonstrated feasibility of a participatory workplace intervention for sick-listed employees with LBP, the results of the present study show that it is also feasible to implement this intervention for sicklisted employees with distress. Despite the existence of stigma related to mental health problems, the employees and supervisors were able to identify obstacles related to mental workload, stress, and communication, to discuss them and to find solutions for these obstacles, whereas such obstacles were seldom discussed by employees with LBP and their supervisors [15, 29]. The RTW coordinator is, in our opinions of crucial importance in discussions about obstacles related to mental workload, stress, and communication. The intermediary role of the RTW coordinator was expected to ensure more equality in the discussion between a sick-listed employee and his or her supervisor, as reported in the focus group meetings prior to our study [17]. Indeed, employees and supervisors perceived that the presence of the RTW coordinator contributed to more equality, safety and support in the meetings. In a study describing the role of RTW coordinators, the competencies of communication and conflict resolution seem to be most the important factors for a successful RTW coordinator [33].

\section{Strengths and Limitations of the Study}

Knowledge about the perceptions of all stakeholders involved is a strength of this study, since stakeholders have different interests in the field of work disability $[14,34,35]$. In previous studies, the perceptions of employees and $\mathrm{OH}$ professionals were considered to be most important [15, 29]. Nowadays, however, the perceptions of supervisors are of great importance for the successful implementation of a workplace intervention, as the supervisor (as employer representative) is a main stakeholder in the field of work disability [34].

Although the satisfaction of all stakeholders was adequate, the $\mathrm{OH}$ professionals favored implementation of the workplace intervention for a specific group of sick-listed employees with distress only. $\mathrm{OH}$ professionals have no intention to apply a workplace intervention in situations with no work-relatedness, in conflict situations, or if good communication about RTW already exists. The former two reasons show similarities with the reasons for not participating in the workplace intervention in this study: 16 out of 56 employees did not participate. For seven of these 16 employees the reason for not participating was RTW, in which case the goal of the workplace intervention had already been achieved. Various different reasons for not starting the intervention were reported for the other nine 
employees. Future studies in the workplace should carefully consider the inclusion and exclusion criteria for employees, to avoid a high number of employees not starting the intervention. On the other hand, $\mathrm{OH}$ professionals reported to intend application of the intervention for communication problems, work-related obstacles for RTW, non-assertive employees, and stagnation of RTW. However, intentions to apply the intervention do not guarantee actual use [36].

Participation in the intervention immediately after sick leave occurred was preferred by the $\mathrm{OH}$ professionals. This was in contrast to the outcomes of the focus groups with all stakeholders, in which application of the workplace intervention after 4 weeks of sick leave was favored [17]. The focus groups indicated that employees often still lack control over their situation and their complaints in the first weeks of sick leave, and stress reduction and reassurance should be the main objectives at that time.

Furthermore, generalization of our results to another context is difficult, partly due to the limited number of companies involved. Large companies usually have work cultures and regulations that differ from small and medium-size companies. On the other hand, large companies encompass a variety of jobs which is an advantage to generalizability. Furthermore, the three participating companies have existing safety and disability practices. With regard to employee benefits, no differences are expected because all companies fall to the same disability legislation. Generalization to other countries is definitely difficult, due to the different benefit systems in different countries, and the existence of stigma related to mental health problems in some countries. Prior to the start of this study, contextual factors were taken into account by performing a small-scale feasibility assessment and conducting focus group interviews [17]. The feasibility assessment indicated a need and a support system for this workplace intervention, and the stakeholders indicated that they would be willing to cooperate in the implementation. The intervention should therefore be tailored to the needs of the stakeholders in the RTW process of sick-listed employees with distress, and this was achieved to a great extent, as shown by the generally positive results of this feasibility study.

\section{Practice Implications}

The results of this study indicate high feasibility for a broad implementation of the workplace intervention. Since the feasibility for LBP, this is the first time that the feasibility has been assessed for sick-listed employees with distress, and the results confirm the expectations of stakeholders that this intervention would be helpful in identifying obstacles and solutions for RTW [17].
Briefly, for broader implementation of the workplace intervention it is essential to devote more attention to aspects related to time-investment, the standardized matrices, and the time at which to start the workplace intervention. Furthermore, application of the intervention was not appropriate for all employees with distress, according to the $\mathrm{OH}$ professionals. For future implementation of this intervention, reconsideration of some application criteria is recommended.

Acknowledgments We would like to thank all employees, supervisors, RTW coordinators and OPs who participated in this study.

Open Access This article is distributed under the terms of the Creative Commons Attribution Noncommercial License which permits any noncommercial use, distribution, and reproduction in any medium, provided the original author(s) and source are credited.

\section{References}

1. Franche RL, Cullen K, Clarke J, Irvin E, Sinclair SJ, Frank JW. Workplace-based return-to-work interventions: a systematic review of the quantitative literature. J Occup Rehabil. 2005; 15(4):607-31. doi:10.1007/s10926-005-8038-8.

2. Zwerling C, Daltroy LH, Fine LJ, Johnston JJ, Melius J, Silverstein BA. Design and conduct of occupational injury intervention studies: a review of evaluation strategies. Am J Ind Med. 1997;32(2): 164-79. doi:10.1002/(SICI)1097-0274(199708)32:2<164::AIDAJIM7>3.0.CO;2-Z.

3. Steckler A, McLeroy KR. The importance of external validity. Am J Public Health. 2008;98(1):9-10. doi:10.2105/AJPH.2007. 126847.

4. Grol R, Grimshaw JM. From best evidence to best practice: effective implementation of change in patients' care. Lancet. 2003;362(9391):1225-30. doi:10.1016/S0140-6736(03)14546-1.

5. Grol R. Knowledge transfer in mental health care: how do we bring evidence into day-to-day practice? Can J Psychiatry. 2008;53(5):275-6.

6. Linnan L, Steckler A. Process evaluation for public health interventions and research; an overview. In: Steckler A, Linnan $\mathrm{L}$, editors. Process evaluation for public health interventions and research. San Francisco: Jossey-Bass; 2002. p. 1-23.

7. Oakley A, Strange V, Bonell C, Allen E, Stephenson J. Process evaluation in randomised controlled trials of complex interventions. BMJ. 2006;332(7538):413-6. doi:10.1136/bmj.332.7538.413.

8. Goldenhar LM, LaMontagne AD, Katz T, Heaney C, Landsbergis $P$. The intervention research process in occupational safety and health: an overview from the national occupational research agenda intervention effectiveness research team. J Occup Environ Med. 2001;43(7):616-22. doi:10.1097/00043764-200107000-00008.

9. Hulshof CT, Verbeek JH, van Dijk FJ, van der Weide WE, Braam IT. Evaluation research in occupational health services: general principles and a systematic review of empirical studies. Occup Environ Med. 1999;56(6):361-77. doi:10.1136/oem.56.6.361.

10. Loisel P, Durand MJ, Berthelette D, Vezina N, Baril R, Gagnon $\mathrm{D}$, et al. Disability prevention-new paradigm for the management of occupational back pain. Dis Manag Health Outcomes. 2001;9(7):351-60. doi:10.2165/00115677-200109070-00001.

11. Nieuwenhuijsen K, Bultmann U, Neumeyer-Gromen A, Verhoeven AC, Verbeek JH, van der Feltz-Cornelis CM. Interventions 
to improve occupational health in depressed people. Cochrane Database of Systematic Reviews (Online: Update Software). 2008; (2), CD006237.

12. Adler DA, McLaughlin TJ, Rogers WH, Chang H, Lapitsky L, Lerner D. Job performance deficits due to depression. Am J Psychiatry. 2006;163(9):1569-76. doi:10.1176/appi.ajp.163.9.1569.

13. Sanderson K, Andrews G. Common mental disorders in the workforce: recent findings from descriptive and social epidemiology. Can J Psychiatry. 2006;51(2):63-75.

14. Frank JW, Sinclair SJ, Hogg-Johnson S, Shannon HS, Bombardier C, Beaton D, et al. Preventing disability from work-related low-back pain. New evidence gives new hope-if we can just get all the players onside. Can Med Assoc J. 1998;158(12):162531 .

15. Anema JR, Steenstra IA, Urlings IJ, Bongers PM, de Vroome EM, van Mechelen W. Participatory ergonomics as a return-towork intervention: a future challenge? Am J Ind Med. 2003; 44(3):273-81. doi:10.1002/ajim.10259.

16. Anema JR, Steenstra IA, Bongers PM, de Vet HCW, Knol DL, van Mechelen W. Multidisciplinary rehabilitation for subacute low back pain: graded activity or workplace intervention or both? A randomized controlled trial. Spine. 2007;32(3):291-8. doi: 10.1097/01.brs.0000253604.90039.ad.

17. van Oostrom SH, Anema JR, Terluin B, Venema A, de Vet HCW, van Mechelen W. Development of a workplace intervention for sick-listed employees with stress-related mental disorders: intervention mapping as a useful tool. BMC Health Serv Res. 2007;7(1):127. doi:10.1186/1472-6963-7-127.

18. Stuart H. Stigma and work. Healthc Pap. 2004;5(2):100-111.

19. Bartholomew LK, Parcel GS, Kok GJ, Gottlieb NH. Intervention mapping: designing theory and evidence-based health promotion programs. Mountain View: Mayfield Publishing Company; 2001.

20. van Oostrom SH, Anema JR, Terluin B, de Vet HCW, Knol DL, van Mechelen W. Cost-effectiveness of a workplace intervention for sick-listed employees with common mental disorders: design of a randomized controlled trial. BMC Public Health. 2008;8:12.

21. Terluin B, van Marwijk HW, Ader HJ, de Vet HCW, Penninx BW, Hermens ML, et al. The four-dimensional symptom questionnaire (4DSQ): a validation study of a multidimensional selfreport questionnaire to assess distress, depression, anxiety and somatization. BMC Psychiatry. 2006;6:34. doi:10.1186/1471244X-6-34.

22. Braam C, van Oostrom SH, Terluin B, Vasse R, de Vet HCW, Anema JR. Validity study of a distress screener. J Occup Rehabil. (submitted).

23. Glasgow RE. RE-AIMing research for application: ways to improve evidence for family medicine. J Am Board Fam Med. 2006;19(1):11-9. doi:10.3122/jabfm.19.1.11.

24. National Institute for Occupational Safety and Health. National occupational research agenda (NORA). Cincinnati: US Department of Health and Human Services; 1996.
25. Stapleton C. Classification scheme. In: Ergonomics abstracts, Vol. 32. London: Taylor \& Francis Ltd.; 2000. p. i-vii.

26. Fleuren M, Wiefferink K, Paulussen T. Determinants of innovation within health care organizations: literature review and Delphi study. Int J Qual Health Care. 2004;16(2):107-23. doi: 10.1093/intqhe/mzh030.

27. Peters MAJ, Harmsen M, Laurant MGH, Wensing M. Space for change. Barriers and possibilities for improvements in patient care [In Dutch: Ruimte voor verandering? Knelpunten en mogelijkheden voor verbeteringen in de patientenzorg]. Nijmegen: Department of Quality of Care (WOK), UMC St Radboud Nijmegen; 2002.

28. Verbeek JH, de Boer AG, van der Weide WE, Piirainen $H$, Anema JR, van Amstel RJ, et al. Patient satisfaction with occupational health physicians, development of a questionnaire. Occup Environ Med. 2005;62(2):119-23. doi:10.1136/oem.2004. 016303.

29. Loisel P, Durand P, Abenhaim L, Gosselin L, Simard R, Turcotte J, et al. Management of occupational back pain: the Sherbrooke model. Results of a pilot and feasibility study. Occup Environ Med. 1994;51(9):597-602. doi:10.1136/oem.51.9.597.

30. van der Weide WE, Verbeek JH, van Tulder MW. Vocational outcome of intervention for low-back pain. Scand J Work Environ Health. 1997;23(3):165-78.

31. Blonk RW, Brenninkmeijer V, Lagerveld SE, Houtman ILD. Return to work: a comparison of two cognitive behavioural interventions in cases of work-related psychological complaints among the self-employed. Work Stress. 2006;20(2):129-44. doi: $10.1080 / 02678370600856615$.

32. Schene AH, Koeter MW, Kikkert MJ, Swinkels JA, McCrone P. Adjuvant occupational therapy for work-related major depression works: randomized trial including economic evaluation. Psychol Med. 2006;37(3):351-62.

33. Shaw W, Hong QN, Pransky G, Loisel P. A literature review describing the role of return-to-work coordinators in trial programs and interventions designed to prevent workplace disability. J Occup Rehabil. 2008;18(1):2-15. doi:10.1007/s10926-007-9115-y.

34. Loisel P, Buchbinder R, Hazard R, Keller R, Scheel I, van Tulder MW, et al. Prevention of work disability due to musculoskeletal disorders: the challenge of implementing evidence. J Occup Rehabil. 2005;15(4):507-24. doi:10.1007/s10926-005-8031-2.

35. Briand C, Durand MJ, St Arnaud L, Corbière M. Work and mental health: learning from return-to-work rehabilitation programs designed for workers with musculoskeletal disorders. Int J Law Psychiatry. 2007;30(4-5):444-57. doi:10.1016/j.ijlp.2007.06.014.

36. Ajzen I. From intentions to action: a theory of planned behaviour. In: Kuhl J, Beckmann J, editors. Action-control: from cognition to behaviour. Heidelberg: Springer; 1985. p. 11-39. 